\title{
Karma Lifli Betonların Tek Eksenli Çekme Altında Çatlak Yapısının İncelenmesi
}

\author{
Burcu AKÇAY ${ }^{1}$
}

ÖZ

Karma lifli betonların kırılmasında lif hacmi ve lif boyutunun etkisi tek eksenli çekme deneyi ile belirlenmiştir. Kemik şeklindeki numuneler serbest dönen mafsallı yükleme düzeneğinde tek eksenli çekme altında yüklenmiştir. Deney sonuçları lif hacmi arttıkça hem çekme dayanımının hem de betonun tokluğunun (yük-deplasman grafiğinin altında kalan alanın) arttığını göstermiştir. Kısa liflerin yalnızca tepe yükünü arttırmadığı uzun lifler ile birlikte karma olarak kullanıldığında tepe yükünden sonraki davranışa da etkiyerek tokluğu da arttırdığı görülmüştür. Görüntü analizleri karma lifli betonlarda çatlağın hiçbir zaman doğrusal olmadığını, betonun iç kısımlarına ilerledikçe dış yüzeyde görünmeyen çoklu çatlamanın, dallanma ve köprülenmenin bulunduğunu göstermiştir. Kısa lifler arttıkça ortalama çatlak alanı belirgin bir şekilde artarken uzun liflerin miktarı arttıkça en büyük çatlak açıklığının arttığı belirlenmiştir.

Anahtar Kelimeler: Çatlak yapısı, dijital görüntü analizi, karma lifli beton, lif geometrisi, lif hacmi, tek eksenli çekme deneyi.

\section{ABSTRACT \\ Crack Pattern Investigation of Hybrid Fibre Reinforced Concrete under Uniaxial Tension}

The effect of size and volume of fibres on the fracture of hybrid fibre reinforced concrete was determined by applying uniaxial tensile test. The bone shaped specimens were loaded under uniaxial tension by using freely rotated support loading test setup. The test results showed that the increase in fibre volume results in an increase in both tensile strength and the area under the load displacement curve, which is the measure of the material toughness. It was shown that the use of short fibres not only increased the peak load but also affected the post-peak behaviour and increased the toughness especially when they were used together with long fibres. The image analyses pointed out that in hybrid fibre reinforced concrete the crack patterns are not in general linear. Instead, the cracks propagate inside the samples

\footnotetext{
Not: Bu yaz1

- Yayın Kurulu'na 30 Nisan 2018 günü ulaşmıştır. 24 Aralık 2018 günü yayımlanmak üzere kabul edilmiştir.

- 31 Mart 2020 gününe kadar tartışmaya açıktır.

- https://doi.org/10.18400/tekderg.419819
}

1 Kocaeli Üniversitesi, İnşaat Mühendisliği Bölümü, Kocaeli - burcu.akcay@kocaeli.edu.tr https://orcid.org/0000-0002-8730-6621 
forming multiple cracks and crack branches as well as developing bridging, though these features are not observed on the surface of the samples. The results showed that with increasing amount of short fibres the average crack area was increased, while the use of long fibres in more abundance increased the width of the largest crack.

Keywords: Crack pattern, digital image analysis, hybrid fibre reinforced concrete, fibre geometry, fibre volume, uniaxial tensile test.

\section{GİRİŞ}

Beton en çok kullanılan yapı malzemesi olmasına rağmen hala bazı yetersizlikleri bulunmaktadır. Basınç gerilmelerine karşı çok iyi bir direnç gösterebilse de çekme gerilmelerinde aynı performansı gösterememektedir. Yüksek olmayan çekme gerilmelerine maruz kaldığında beton çatlar; bir kez çatladığında bu çatlak çok hızlı genişler ve ilerler, bu durum da düşük tokluk özeliğine neden olur. Bu sorunu çözebilmek için betona değişik tipte lifler katılabilmektedir. Birçok çeşit lif ilave edildiğinde betonun yalnızca tokluğu artarken, çekme dayanımında belirgin bir artış olmamaktadır. Her iki özelikte de iyileştirmeler elde edebilmek amacıyla oluşturulan karma lifli betonlarda kısa lifler çekme dayanımını arttırırken uzun lifler şekil değiştirme kapasitesini ve böylece betonun sünekliğini arttırır [111]. Karma lifli betonlarda liflerin etkin bir şekilde çalışabilmesini sağlayabilmek için beton fazının da iyi optimize edilmiş, yoğun bir mikro yapıda olması gerekir. Böyle bir karışımı oluşturabilmek için işlenebilirliğin de gerekli seviyede olması sağlanır. $\mathrm{Bu}$ şekilde tasarlanmış karışımlar ile yüksek/ultra yüksek performanslı betonlar elde edilebilir ve böylece imalat ile servis ömrü boyunca üstün nitelikler gerektiren yapı ve yapı elamanlarında kullanılabilir.

Karma lifli betonların gerilme-şekil değiştirme davranışının Lineer Elastik Kırılma Mekaniği ya da Lineer Olmayan Elastik Kırılma Mekaniği (kohezif modeller) ile tanımlamak malzemenin sünek olması nedeni ile kolay değildir. Van Mier [12, 13] lifli betonların gerilme-şekil değiştirme davranışının elastik, mikro çatlama (stabil), makro çatlama (stabil olmayan) ve köprülenme olmak üzere dört ayrı bölgede incelenebileceğini göstermiştir. Bilindiği gibi kısa ince lifler tepe yükü öncesi mikro çatlama bölgesindeki mikro çatlakları önler ve köprülerken, uzun lifler köprülenme bölgesindeki makro çatlakları önlerler. Bu iyileştirmelerin kombinasyonu ile karma lifli betonlar, gelişmiş mekanik ve kırılma özelikleri gösterirler. Bu tip malzemenin kırılma davranışını belirleyebilmek için deneysel veriler üzerinde çalışılması ve üst düzey kalite kontrol yapılması gerekir. Gerilme-şekil değiştirme davranışı yapısal etkilerden arındırılmış doğal hali ile belirlenerek yapısal eleman analizlerine doğru veriler aktarılmalıdır. $\mathrm{Bu}$ durumda da deney yöntemleri önem kazanmaktadır.

Yapısal etkileri en aza indirebilmek için tek eksenli çekme yükleme durumu tercih edilir [14]. Bu durumda Mod-I açılma tipi kırılma görüleceği için yarı gevrek betonların ve sünek lifli betonların gerçek davranışı elde edilebilir. Bu tip deneylerde dikkate alınması gereken diğer konu da deneyde uygulanan sınır şartlarının etkisidir. Tek eksenli çekme deneyinde temel olarak tercih edilebilen sabit sınır ya da serbest dönen sınır şartları olabildiği gibi kontrollü sınır şartları olarak anılan üçüncü bir tip de bulunmaktadır [15]. Dönen sınır şartları numunenin uçlarının deney boyunca serbestçe dönebildiği durum iken sabit sınır şartlarında bu dönme deney düzeneğindeki eğilme rijitliği ile önlenir. Kontrollü sınır şartlarında ise üç 
hidrolik yük vericiler ve deformasyon ölçerler (LVDT) kullanılarak deney boyunca numunenin paralel durması sağlanır. Bazı durumlarda kontrol edilen bölge numunenin tamamı veya numunenin sadece orta kısmı olabilir. Kontrollü sınır şartları diğer iki yönteme göre daha az tercih edilen bir yöntem olmuştur [15].

Sabit ve dönen sınır şartlarının numunenin tek eksenli çekme altındaki davranışı üzerindeki etkisi Şekil 1.1'de görülmektedir [16]. Sabit sınır şartları altında eksantrik dış yükler nedeniyle çatlak oluşumu numunenin bir yüzünde başlar ve deney düzeneğinin eğilme momenti karşılığı ile devam eder. Bu eğilme momenti nedeni ile numunenin diğer yüzünde ikinci bir çatlak oluşumu başlar. Bu durum yük-deplasman eğrisinin yumuşama kısmının tipik platosunu oluşturur. Diğer yandan dönen sınır şartları uygulandığında, önleyici eğilme momentleri oluşmayacağından tek bir ana çatlak oluşur ve numune boyunca devam eder. Kontrollü sınır şartlarında ise yapısal etkiler sabit sınır şartlarından bile daha belirgindir ve üniform deformasyon dağılımı oluşur. Gerçekte yapı içerisinde iki sınır uç paralel tutulsa dahi deformasyon dağılımı üniform olmamaktadır. Van Mier vd. [17] her üç yöntemi karşılaştırdığında kontrollü sınır şartlarının diğer iki yönteme göre kırılma enerjisini çok büyük hesapladığını göstermiştir. En düşük değerin dönen sınır şartlarında bulunması bu yöntemde sınır değer şartlarının etkisinin minimize edildiğini göstermiştir. Hem dönen hem de sabit sınır şartlı tek eksenli çekme deneyinin bazı avantaj ve dezavantajları olduğundan hangisinin uygulanabileceği hala tartışma konusudur [18]. Ancak, bugüne kadar henüz standart bir çekme deneyi belirlenmediği gibi standart çekme deney numunesi de tanımlanmamıştır. Prizma, silindir (çentikli veya çentiksiz), kalın veya ince kemik ve halter (dambıl) şeklinde numuneler üzerinde çekme deneyi yapılmaktadır.
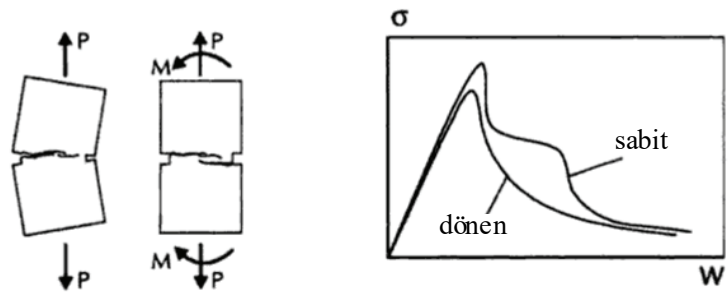

(a)

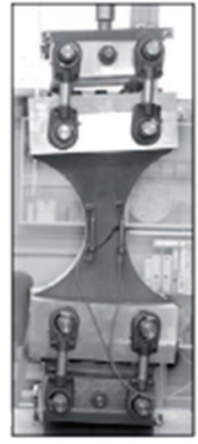

(b)

Şekil 1.1 - (a)Tek eksenli çekme deneyinde sınır şartlarının etkisi ve (b) serbest dönen sınır şartlı deney düzeneğinde kırılmış numune [17].

Kırılma enerjisinin yanında, tepe yükü de sınır değer şartlarından etkilenir. Dönen sınır şartlarında göçme numunenin en zayıf noktasında sınır değer şartlarından bağımsız olarak oluşur [19, 20]. Aynı zamanda dönen sınır şartlarında sonuçların dağılımı sabit sınır şartlarından daha yüksek olması da numunenin kendi içyapısından etkilendiğini, sınır şartlarının etkisinin olmadığını göstermektedir. Her ne kadar dağılım yüksek olsa da dönen sınır şartlarının çatlak oluşumu ve kırılma davranışını incelemede tercih edilebilme nedenleri: deformasyonun üniform olmaması; sınır şartlarının etkisinin minimize olması; deney düzeneğinden gelen eğilme rijitliğinin neden olduğu yapısal etkilerin altında olmaması 
olarak sıralanabilinir. Belirgin bir toklaşma bölgesi gösteren lifli betonlarda kırılma davranışını inceleyebilmek için yapısal etkilerin azaltılması gerekir. Özellikle lifli betonlarda çatlak oluşumundan sonra deformasyon dağılımının değişmesi ile çatlağın genişlemesine ve ilerlemesine karşı duran liflerin çalışmasının etkisini görebilmek için de dönen sınır şartları yöntemi faydalı olacaktır. Literatürde daha çok sabit sınır şartları altında lifli betonun performansı incelenmiş $[10,21,22]$, dönen sınır şartlarında ise incelemeler sınırlı kalmıştır. Naaman vd. [22] ince numunelerde farklı çekme deneyi sonuçlarını incelemiş ve farklı mesnet şartlarının (sabit ve dönen) ile numune şekillerinin (çentikli ve çentiksiz) lifli betonların farklı çeşitlerinde kullanılabileceğini önermiştir. Karma lifli betonlarda ise çentiksiz numunelerin kullanılması ve dönen sınır şartlarını kesinlikle önermiştir.

Daha önce yapılan çalışmada serbest dönen mesnetli tek eksenli çekme altında üç farklı lif hacmi içeren dört farklı boyuttaki kemik şeklindeki karma lifli betonların boyut etkisi detaylı olarak incelenmiştir [23]. Bu çalışmada ise seçilen tek bir boyuttaki karma lifli betonların deney sonuçları verildikten sonra yük-deplasman davranışı çatlak ilerleme mekanizmaları ile incelenmiş, çatlak yapısının sayısal ve analitik karşılaştırmaları ile lif miktarının etkisi irdelenmiştir.

\section{DENEYSEL ÇALIŞMA}

\subsection{Karma Lifli Beton Karışımları}

Bu çalışmada kullanılan deneysel veriler önceki bir çalışma [23] kapsamında gerçekleştirilen tek eksenli çekme deneyi sonuçlarından alınmıştır. Beton karışımları, numune özelikleri ve tek eksenli çekme deneyi ile ilgili bilgiler Akcay [23] tarafından detaylı olarak sunulmuş olduğundan bu yazıda bu bilgilere kısaca yer verilecektir. Benzer matriste ancak hacimce \%3, 4 ve 5 gibi farklı miktarlarda lif içeren üç değişik karışım hazırlanmıştır. Düz uçlu benzer çekme dayanımında (2400 MPa) olan çelik lifler, iki farklı geometrik narinlik oranında kullanılmıştır. Kısa liflerin çapları $0.15 \mathrm{~mm}$ ve boyları $6 \mathrm{~mm}$ iken uzun liflerin çapları

Tablo 2.1 - Karma lifli betonların karışım miktarları ve bazı mekanik özelikleri.

\begin{tabular}{lccc}
\hline & KLB-\%3 [2+1] & KLB-\%4 [2+2] & KLB-\%5 [4+1] \\
\hline Çimento (CEM I 52.5) & 960 & 968 & 958 \\
Silis dumanı & 91 & 92 & 91 \\
Uçucu kül & 161 & 162 & 161 \\
Kum (0-1 mm) & 724 & 731 & 722 \\
Su & 218 & 220 & 217 \\
Yüksek oranda su azaltıcı katkı & 20.93 & 22.16 & 23.95 \\
Kısa lif & 150.80 & 153.78 & 309.01 \\
Uzun lif & 75.40 & 153.78 & 79.23 \\
\hline Akış çapı [mm] & 63 & 45 & 45 \\
\hline Basınç dayanımı [MPa] & 130 & 134 & 133 \\
Elastisite Modülü [GPa] & 36.3 & 36.6 & 37.8 \\
\hline
\end{tabular}


$0.2 \mathrm{~mm}$ ve boyları $12 \mathrm{~mm}$ 'dir. Su/çimento oranı (0.23) ve su/bağlayıcı oranı (0.18) sabit olan matris CEM I 52.5 çimentosu, silis dumanı ve uçucu külden üretilmiş ve yüksek oranda su azaltıcı katkı ile kıvamı ve işlenebilirliği yeterli, homojen karışımlar elde edilmiştir. Karışım oranlarının verildiği Tablo 2.1'de görüldüğü gibi ilk karışım (KLB-\%3) \%2 kısa lif ve \%1 uzun lif içerirken, ikinci karışım (KLB-\%4) \%2 kısa ve \%2 uzun lif içermektedir. Üçüncü karışım (KLB-\%5) ise \%4 kısa lif ve \%1 uzun lif ilavesi ile üretilmiştir. Böylece hem toplam lif miktarının hem de lif geometrisinin etkisi incelenmiştir. KLB-\%3 ve KLB-\%4 serilerinin karşılaştırılması ile uzun lif miktarı arttığındaki etkiler, KLB-\%3 ve KLB-\%5 serilerinin karşılaştırılmasında ise kısa lif miktarı arttırıldığındaki etkiler belirgin bir şekilde ortaya konulmuştur. Her bir seri tek seferde üretilmiştir. Betonların işlenebilirliğini istenen seviyelere getirebilmek için büyük miktarlarda yüksek oranda su azaltıcı katkı kullanılmıştır. \% 3 oranında lif içeren karışımın akış çapı $63 \mathrm{~mm}$ iken, diğer iki seride daha fazla katkı kullanmamak için akış çapı $45 \mathrm{~cm}$ olacak şekilde üretilmiştir.

\subsection{Numune Özelikleri}

Karma lifli betonlarda tek eksenli çekme deneyi yapabilmek için kemik şeklinde numuneler kullanılmıştır. Bu tip numunelerin çekme dayanımını belirlemede tercih edilen bir yöntem olduğu bilinmektedir [14, 17, 24, 25]. Olası duvar etkilerini azaltmak ve gerilme ile şekil değiştirme gibi sürekli değişkenleri temsil edebilecek hacme ulaşabilmek için numune kesitinin en küçük boyutunun kullanılan lif uzunluğunun en az üç katı olmasına dikkat edilmesi gerekir [21]. Kemik numunelerinde diğer önemli bir konu da numunede oluşturulacak olan körfezler ile keskin kenarlardan eğimli kenarlara geçişin sağlanarak gerilme yığılmalarının önlenmesidir [14]. Bu nitelikler göz önüne alınarak en küçük kesiti $100 \mathrm{~mm} \times 100 \mathrm{~mm}$, boyu $500 \mathrm{~mm}$ olan Şekil 2.1'de şematik olarak da görülebilen numuneler üretilmiştir. Numunelerin alt ve üst sonları kesildikten sonra bir yapıştırıcı ile alüminyum plakalar yapıştırılmıştır. Bu plakalar ile daha sonra yükleme düzeneğine bulonlar yardımıyla bağlanmıştır.

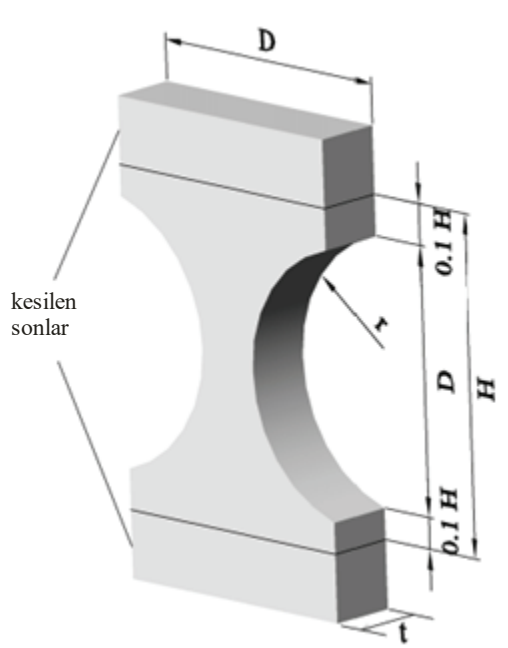

$$
\begin{aligned}
& H=500 \mathrm{~mm} \\
& D=400 \mathrm{~mm} \\
& r=200 \mathrm{~mm} \\
& t=100 \mathrm{~mm}
\end{aligned}
$$

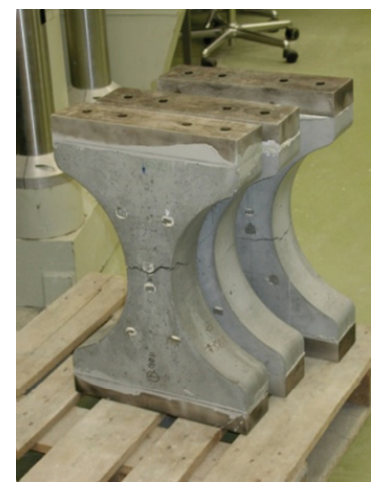

Şekil 2.1 - Tek eksenli çekme deneyi için hazırlanmış kemik numunelerin biçim ve boyutları. 
Basınç dayanımını ve elastisite modülünü belirlemek için ise $150 \mathrm{~mm}$ çapında $300 \mathrm{~mm}$ yüksekliğinde silindir numuneler kullanılmıştır. Hazırlanan numuneler puzolan içerdikleri için üretimden 56 gün sonra test edilmiştir. Her bir serinin basınç dayanımı ve elastisite modülü sonuçları Tablo 2.1'de verilmiştir. Bulunan değerler beş numunenin ortalamasıdır. Tabloda da görüldüğü gibi yüksek dayanımlı bir beton fazı karışımların hepsinde elde edilmiştir.

\subsection{Tek Eksenli Çekme Deneyi}

Kemik şeklindeki numunelerde tek eksenli çekme deneyi dönen sınır şartlarında yapılabilmesi için pandül çubuklar kullanılarak kuvvetlerin merkezi kalması ve mesnetlerin serbestçe dönebilmesi sağlanmıştır. Şekil 2.2'de görüldüğü gibi sekiz adet pandül çubuk kullanılmış ve bu çubuklar üst ve alt mesnetleri birbirine bağlamıştır. Yükleme çerçevesi içerisine numune sonlarındaki iki ortoganal doğrultuda serbestçe dönebilen mafsallar yerleştirilmiştir. Numune sonları iki yatay geçiş çubuğu ve dörder pandül çubuk ile mafsal yapısına bağlanmıştır. Pandül çubukların bu geçiş çubuklarına mafsallar ile bağlanması ile sistemin $360^{\circ}$ düzlem içi yönünde, $8^{\circ}$ düzlem dışı yönünde dönmesine izin verilmiştir. $\mathrm{Bu}$ pandül çubuklar sayesinde hidrolik yükleyiciden gelen kuvvet pandül çubuklarda dört kuvvete bölünmüş ve yükleme plakasına bağlı olan geçiş çubuğu ile numune kalınlığ1 boyunca dağılmıştır. Her bir pandül çubuğun uzunluğu 270 mm'dir. Mesnetin dönme eksen merkezi numune ve yapıştırılan plakanın ara yüzeyinin ortası olarak belirlenmiştir. Benzer deney düzeneği daha önce birçok araştırmacı tarafından kullanılmıştır [14, 23, 26, 27, 28 ]. Test aletinin yükleme hücresinin kapasitesi 200 kN'dur.

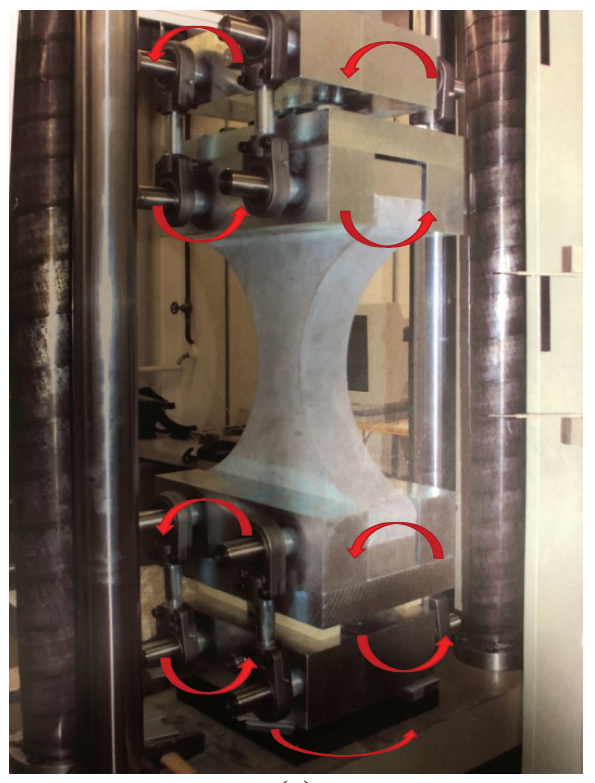

(a)

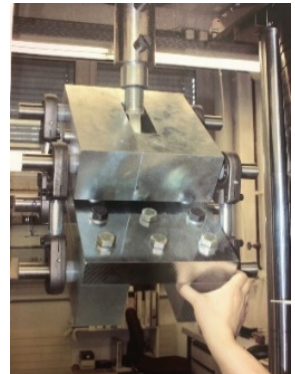

(b)
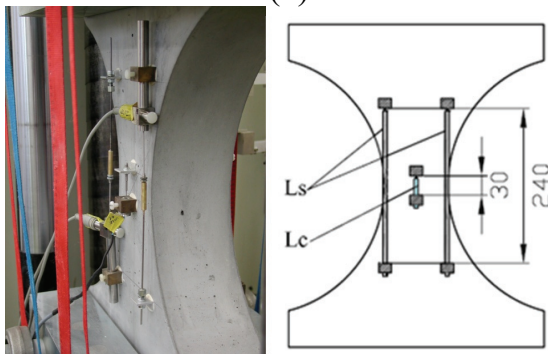

(c)

Şekil 2.2 - (a)Tek eksenli yükleme deney düzeneği (oklar numunenin dönme merkezi etrafindaki dönebilme kabiliyetini göstermektedir), (b) serbest dönebilen mafsal sistemi ve (c) LVDT'lerin yerleşimi. 
Numunedeki deformasyonları ölçmek için her bir yüze üçer tane LVDT eklenmiştir (Şekil 2.2). Numune yüzeyinin kenarlarında olan LVDT'lerin $\left(\mathrm{L}_{\mathrm{s}}\right)$ ölçü boyu $240 \mathrm{~mm}$ iken tam merkeze yerleştirilmiş olan LVDT'nin $\left(\mathrm{L}_{\mathrm{c}}\right)$ ölçü boyu $30 \mathrm{~mm}$ 'dir. Merkeze yerleştirilen LVDT'ler küçük deplasmanlarda deneyler arasındaki tutarlılığı gözlemlemek için kullanılmıştır.

\section{4. Çatlak yapısı incelemeleri}

Çekme deneyi sonrasında oluşan çatlakları ve hasarı belirleyebilmek için vakum doyurma yöntemi uygulanmıştır [16]. Yüklemeden sonra boyun bölgesindeki kırılmış kısım elmas daire ile kesilerek bir kutunun içerisinde vakuma yerleştirilmiştir. Daha sonra kutu vakum altında yeteri süre bekletildikten sonra flüoresans epoksi reçine ile doldurulmuştur. Böylece numune içerisindeki tüm boşluk, kusur ve çatlaklar bu reçine ile doyurulmuştur. Reçine sertleştikten sonra elmas daire ile örnekler yükleme doğrultusuna dört paralel dilime ayrılmıştır. Her bir dilimin her iki yüzeyi de mor ötesi ışık altında dijital olarak görüntülenmiştir. Daha sonra görüntü inceleme programları ile analiz edilerek, çatlak ve kusurların yerleri ve geometrik özelikleri tespit edilmiştir.

\section{SONUÇLARIN İRDELENMESİ}

\subsection{Yük-Deplasman Eğrileri}

Yukarıda da belirtildiği gibi bu yazıdaki deney sonuçları, önceki bir çalışmada [23] sunulan beton örneklerinin tek eksenli çekme altındaki yük-deplasman eğrilerinden alınmıştır. Bu çalışmada ise bu deneysel veriler kullanılarak lifli betonların tokluk parametreleri elde edilmiş, yükleme altında oluşan çatlakların incelenmesi ile elde edilen çatlak alanı ve en büyük çatlak açıklığı değerleri irdelenerek yeni sonuçlara ulaşılması amaçlanmıştır. Şekil 3.1 'de $\% 2$ k1sa ve $\% 1$ uzun lif içeren KLB-\%3 serisine ait bir numunenin yük-deplasman eğrisi görülmektedir. Bu diyagramda numunenin hem arka hem de ön yüzüne iliştirilmiş olan LVDT sonuçları farklı değerler göstermektedir. Pandül çubuklar sayesinde serbestçe dönebilen mesnetler yardımıyla Mod-I çatlak açılmasının oluştuğu görülmektedir. Çatlağın açıldığı yüzdeki LVDT ölçümleri uzama gösterirken çatlak ağzının arka tarafında kısalma göstermiştir. LVDT'lerin kısalma göstermesi çatlak açılmasının arkasındaki bölgelerin basınç altında olduğuna işaret eder [23].

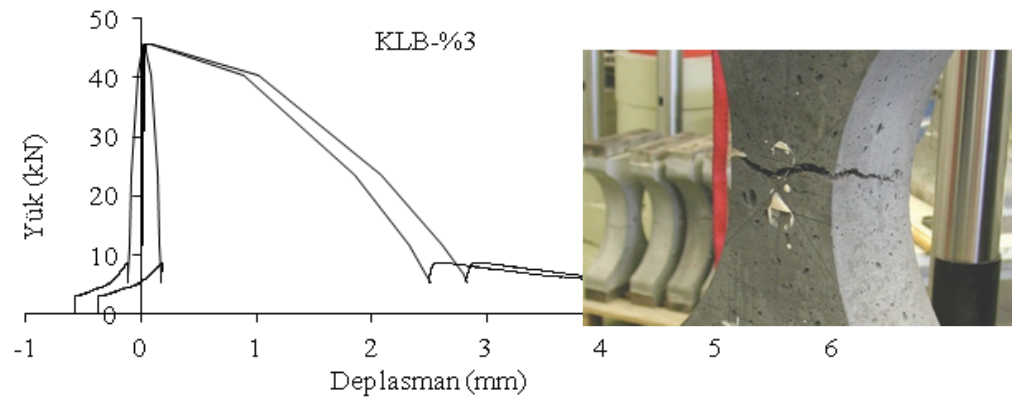

Şekil 3.1 - KLB-\%3 serisine ait bir örneğin yük-deplasman ĕgrisi 
Çatlak numunenin ön yüzünden arka yüzüne doğru ilerlemiştir. Bazı durumlarda arkadaki LVDT'ler hızla kısalma değeri verirken ön yüzdeki LVDT'lerin tepe yükünde çok sivri olmayan değerler vermesi durumunda ise ön yüzden arka yüze doğru çatlak ilerlerken başka bir çatlağın da ilerlemesi gözükür. Diğer bir kırılma şeklinde ise tüm LVDT'lerde uzama değerleri alınır ancak arka yüzdeki LVDT'lerdeki bu değerler ön yüzdekine göre daha düşüktür. Bu durum tüm kesitin simetrik olarak çekme altında olduğunu, ön yüzün her iki tarafında da çatlakların başlayıp arka yüze doğru ilerlediğini gösterir. Son duruma özellikle yüksek oranda lif kullanıldığı zaman karşılaşılmıştır. Deneyler, tepe yükten önce oluşan çoklu çatlakların, tepe yükten sonra tek bir ana çatlakta yerelleştiğini göstermiştir. Çoklu çatlama ince kısa liflerin miktarının artırılması ile elde edilebilirken uzun lifler yerelleşmiş makro çatlağın köprülenme miktarını çoğaltmıştır.

Şekil 3.2 üretilen tüm karma lifli betonların LVDT'lerden alınan ortalama deplasman değerlerine göre belirlenmiş yük-deplasman diyagramlarını göstermektedir. Diyagramlardaki eğriler ortalamayı temsil eden numuneyi, taralı alanlar ise diğer numunelerin eğrilerinin bulunduğu alanları belirlemektedir.
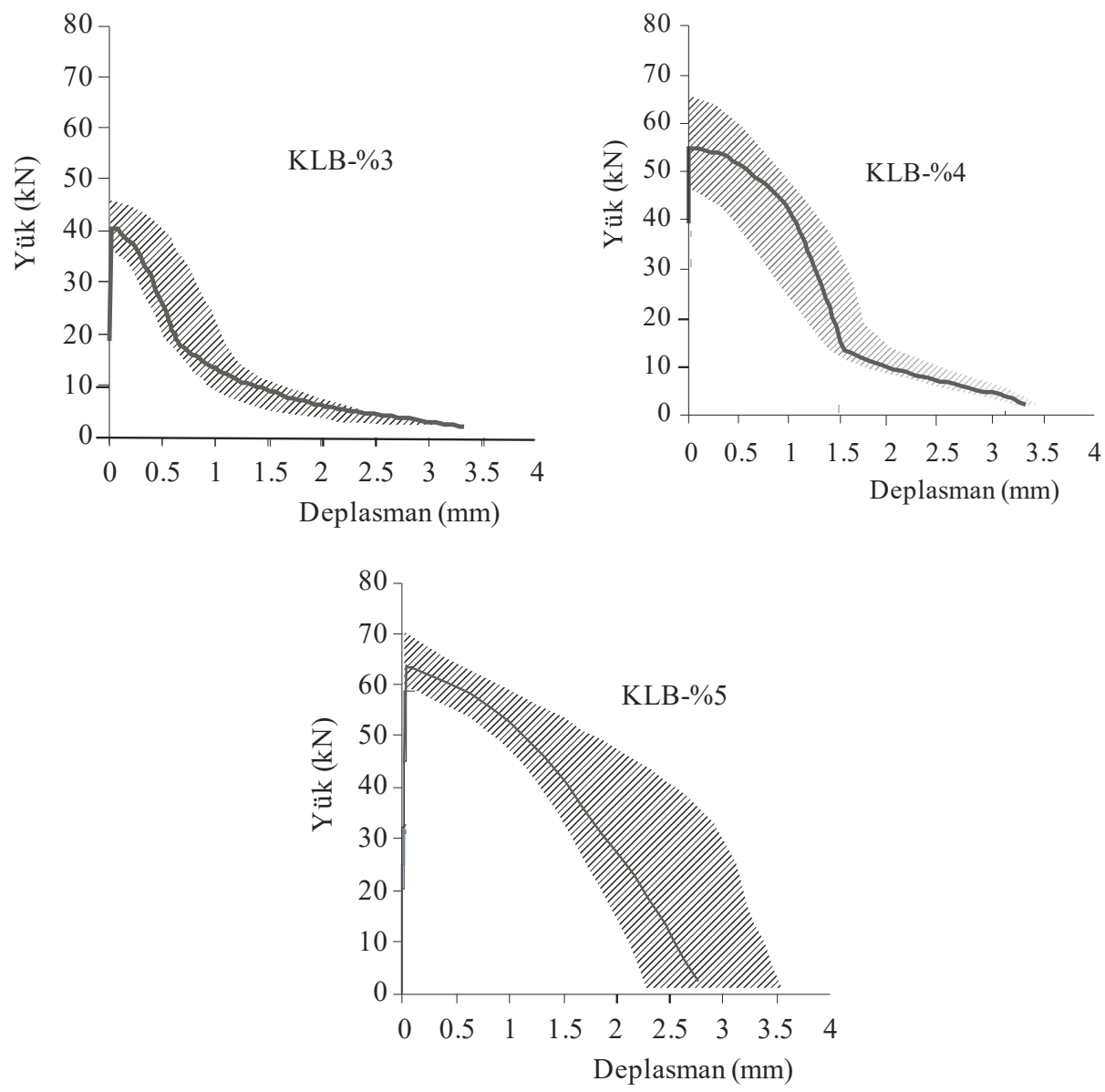

Şekil 3.2 - Tüm karışımların yük-deplasman ĕgrileri [23]. 
Sonuçlar, artan lif miktarı ile tepe yükün arttığını göstermektedir. Beklenildiği gibi, tepe yükteki deplasman ve tepe yük sonrası köprülenme bölgesi artan lif miktarı ile artmıştır. Bu üç beton benzer matrise sahip olsa da (Tablo 2.1'de verildiği gibi benzer basınç dayanımına sahiptirler), çatlama alanındaki artan lif miktarı daha fazla lif köprülenmesi ile sonuçlanmıştır. Diğer yandan, sıyrılan lif miktarı çatlama mekanizmasındaki diğer bir faktördür. Çekip-çıkarma süreci rijitliği azaltır ve yük-deplasman eğrisinde tepe yükten önce lineer olmayan davranışa neden olur [23].

Tüm karışımların deney sonuçları ile her bir serinin ortalama ve standart sapma değerleri Tablo 3.1'de verilmiştir. Tablodan görüldüğü gibi lif hacmi arttıkça hem çekme dayanımı hem de betonun tokluğu artmıştır. Uzun liflerin hacminin \%1'den \%2'ye artması ile çekme dayanımı 4.53 MPa'dan 5.60 MPa'a yükselirken, kısa liflerin hacminin \%2'den \%4'e çıkması çekme dayanımını $6.44 \mathrm{MPa}$ seviyesine, tokluğunu da iki katından fazla bir seviyeye getirmiştir.

Tablo 3.1 - Tüm numunelerin deney sonuçlarl, ortalama ve standart sapma değerleri.

\begin{tabular}{|c|c|c|c|c|}
\hline & numune no & $\begin{array}{l}\text { Çekme dayanımı } \\
(\mathrm{MPa})\end{array}$ & $\begin{array}{l}\text { Yük-deplasman eğrisinin } \\
\text { altında kalan alan }(\mathrm{Nm})\end{array}$ & $\begin{array}{c}\text { Tepe yükü } \\
\text { deplasmanı }(\mathrm{mm})\end{array}$ \\
\hline \multirow{7}{*}{$\begin{array}{l}\tilde{\partial} \\
\partial \\
\ddot{n} \\
\vec{\nabla}\end{array}$} & 1 & 5.22 & 64.4 & 0.0337 \\
\hline & 2 & 4.38 & 51.7 & 0.0920 \\
\hline & 3 & 4.55 & 49.5 & 0.0550 \\
\hline & 4 & 4.02 & 40.9 & 0.0254 \\
\hline & 5 & 4.46 & 57.1 & 0.0323 \\
\hline & ortalama & 4.53 & 52.7 & 0.0477 \\
\hline & standart sapma & 0.44 & 8.7 & 0.0272 \\
\hline \multirow{7}{*}{ 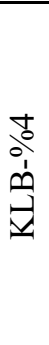 } & 1 & 5.26 & 67.8 & 0.0356 \\
\hline & 2 & 4.56 & 52.0 & 0.1798 \\
\hline & 3 & 6.46 & 85.9 & 0.0658 \\
\hline & 4 & 5.39 & 87.4 & 0.0326 \\
\hline & 5 & 6.32 & 32.2 & 0.0433 \\
\hline & ortalama & 5.60 & 65.1 & 0.0714 \\
\hline & standart sapma & 0.8 & 23.4 & 0.0620 \\
\hline \multirow{7}{*}{$\begin{array}{l}a \\
\dot{0} \\
\dot{1} \\
\vec{\theta} \\
\vec{v}\end{array}$} & 1 & 6.84 & 57.9 & 0.0338 \\
\hline & 2 & 6.35 & 109.0 & 0.0446 \\
\hline & 3 & 7.03 & 163.4 & 0.0382 \\
\hline & 4 & 6.13 & 190.8 & 0.0926 \\
\hline & 5 & 5.87 & 89.3 & 0.0325 \\
\hline & ortalama & 6.44 & 122.1 & 0.0483 \\
\hline & standart sapma & 0.5 & 54.3 & 0.0252 \\
\hline
\end{tabular}


Kısa liflerin yalnızca tepe yükünü arttırmadığı uzun lifler ile birlikte karma olarak kullanıldığında tepe yükünden sonraki davranışa da etkiyerek tokluğu da artırdığı görülmüştür (Şekil 3.3). Numune geometrisinde seçilen eğrisel körfezler sayesinde taze haldeki karma lifli beton kalıbın boyun bölgesinden hızla geçmiştir ve böylece liflerin önemli bir kısmı yükleme doğrultusuna paralel yönelmiştir. Prizmatik numunelerde görülen duvar etkisiyle lif yöneliminin değişmesinin mekanik performans üzerindeki etkisi kemik numunelerde kullanılan geometrik biçim nedeniyle daha azdır. Serbest dönen mafsal sisteminde daha önce de bahsedildiği gibi malzemedeki çatlak oluşumu yapısal etkilerden arındırıldığı için içyapı kontrolünde kırılır ve bu yüzden sonuçlar dağınık çıkmaktadır. Standart sapma değerleri yüksek de olsa uzun liflerin hacminin artmasıla tepe yükündeki deplasman değerinin de arttığı söylenebilir.
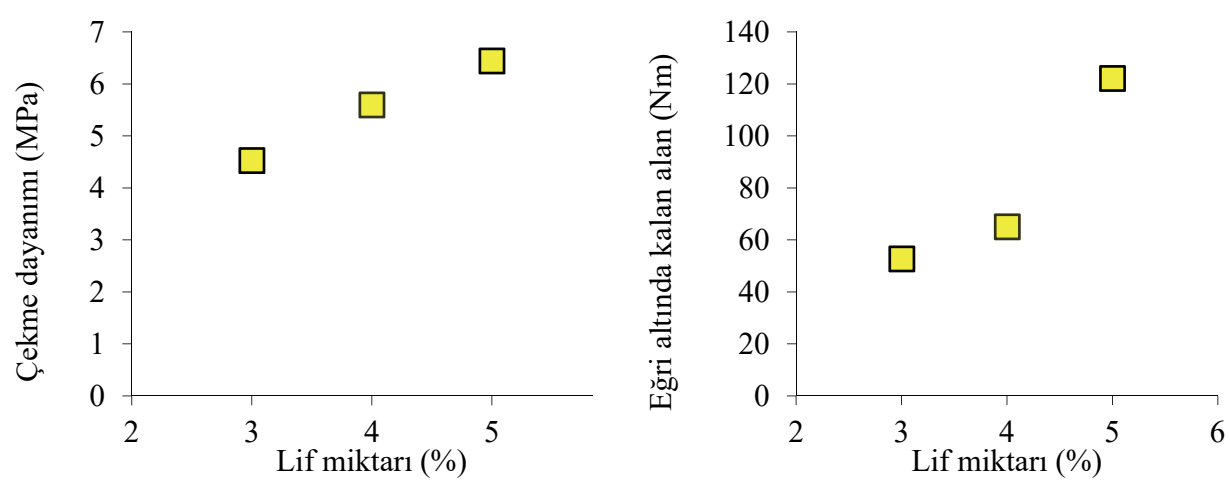

Şekil 3.3 - Lif miktarının çekme dayanımı ve yük-deplasman ĕgrisinin altında kalan alan ile ilişkisi.

\section{2. Çatlak Yapısının İncelenmesi}

Şekil 3.4’ te her bir karma lifli beton serisinden çatlak açılmanın başladığı yüze paralel alınan ilk kesitteki mor ötesi ışık altındaki çatlak yapıları görülmektedir. Mod-I açılma şeklindeki çatlakların üç karma lifli beton serisinde de görüldüğü belirlenmiştir [23].

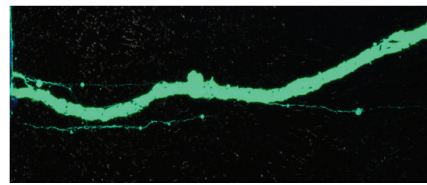

KLB- $\% 3$

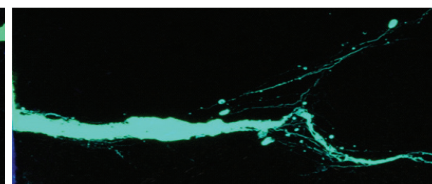

KLB-\% $\%$

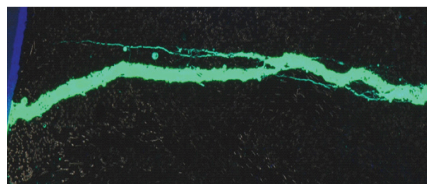

KLB- $\% 5$

Şekil 3.4 - Karışımların çatlak açılmanın olduğu ön yüzdeki ilk kesitlerinin görüntüleri [23].

Çatlak ilerlemesinin karma lifli betonun içyapısı ve lif dağılımı ile ilişkisi KLB-\%5 serisinde açıklanmıştır. Şekil 3.5 'te görüldüğü gibi hacimce $\% 5$ oranında lif içeren karışımda lif dağılımı çatlak ilerleme mekanizmasında etkili olmuştur. 


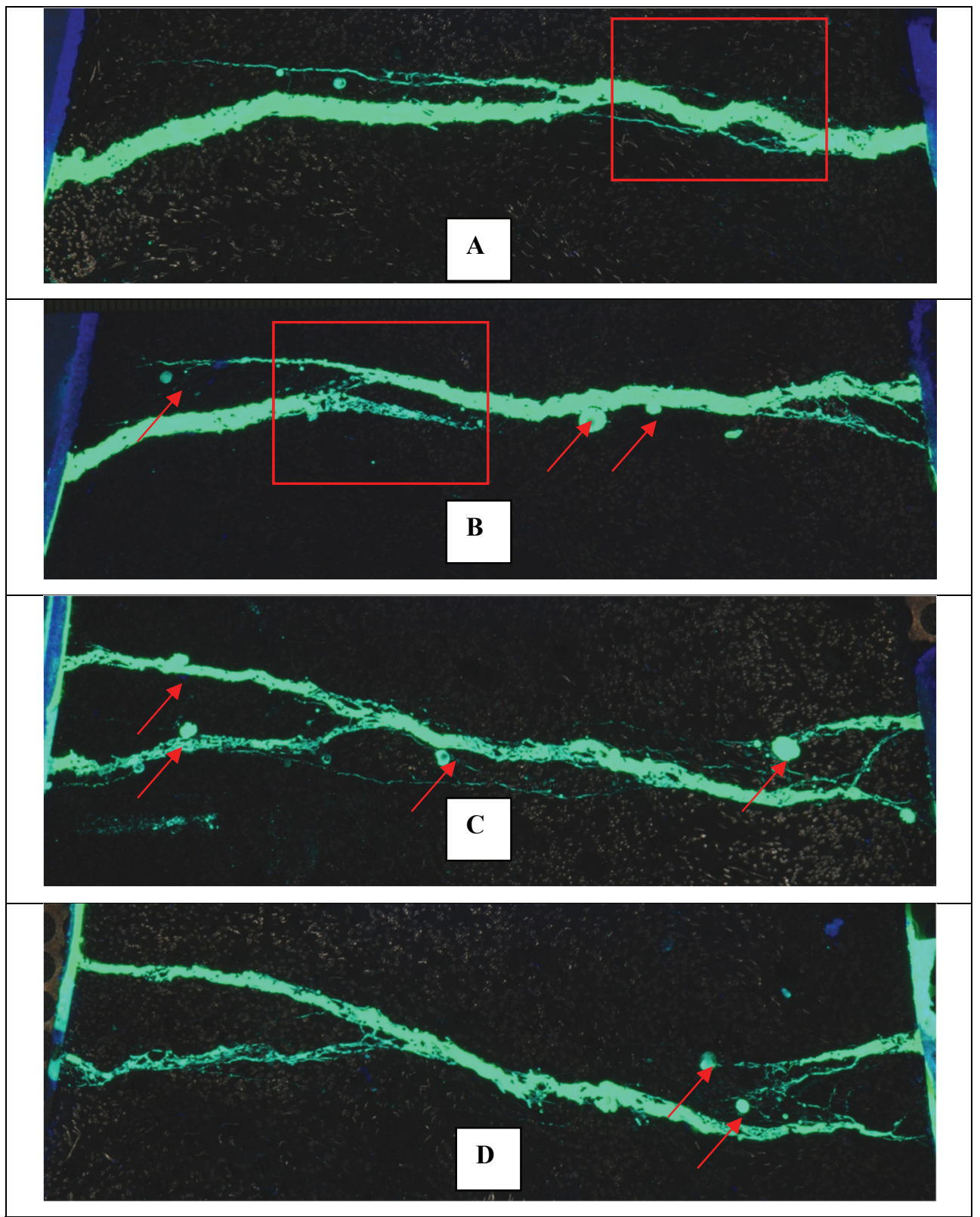

Şekil 3.5 - KLB-\%5 serisinde kırılma alanından alınan dört dilimdeki çatlak yapıları.

Çatlak ağZı açılmasının başladığı A kesitinde dikdörtgen ile belirtilen yerde liflerin yüklemeye paralel doğrultuya yakın yönelmeleri ve lif miktarının beton matrisin diğer bölgelerine göre az olması nedeni ile çatlağın yön değiştirdiği görülmektedir ( $\mathrm{Bu}$ etki Şekil 3.6'da verilen fotoğrafta daha belirgin bir şekilde görülmektedir). Çatlak ağzından 
uzaklaştıkça Şekil 3.5'teki B, C ve D kesitlerinde çatlak dallanma mekanizmalarının çalıştığ1 beton matris fazı içerisindeki boşluklara (bir kısmı kırmızı oklar ile belirtilen) doğru yeni kollar oluştuğu görülmektedir. Buradan çatlak yönünü belirleyen etkili faktörün liflerden daha çok boşluklar olduğu söylenebilir. Çatlaklar büyük oranda matris fazındaki boşlukları birleştirecek şekilde yönelim göstermektedir. B kesitinde ise liflerin çatlak köprülenme mekanizmasına etkisi görülmektedir. Lifler çatlakları açılmasını önleyecek şekilde köprüler. Bu görüntüler aynı zamanda beton dış yüzeyinde sadece tekil bir çatlak görünmesine rağmen betonun iç kısımlarına ilerledikçe dış yüzeyde görünmeyen farklı çatlakların oluştuğunu, dallandığını ve köprülendiğini de göstermiştir.

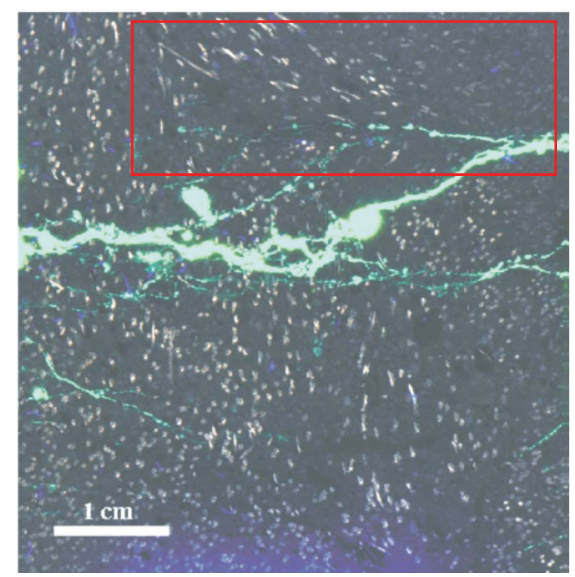

Şekil 3.6 - Çatlak yönelmesi ve dallanmasının lif dă̆llımından etkilenmesi.

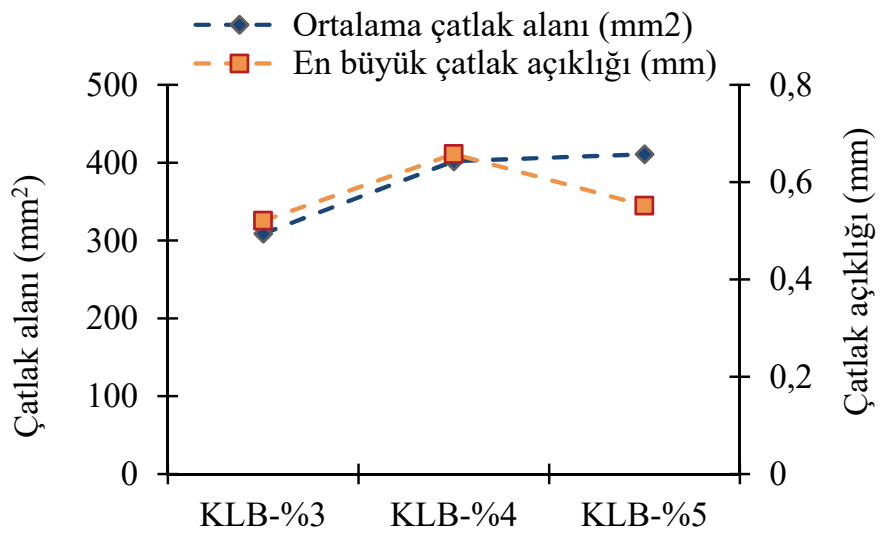

Şekil 3.7 - Üretilen karma lifli betonların dijital görüntü analizleri ile bulunan çatlak alanı ve çatlak açıklı̆̆ de ğerleri (Her bir değer iki farklı numuneden alınan sonuçların ortalamasıdır). 
Her bir karma lifli beton karışımının iki numunesinde görüntü analizleri yapılmıştır. Bu analizlerde görüntülerdeki çatlak alanları ve yüklemeye paralel yöndeki en büyük çatlak açıklıkları belirlenmiştir. Her bir dilimdeki görüntüler önce ikili hale getirilerek gri skalalı alanlar ile çatlakların yerleri ve geometrileri belirlenmiş, daha sonra bu alanlar yazılım sayesinde hesaplanmıştır. Bu hesaplamalarda numuneler içindeki çeşitli boşluklar da çatlak veya kusur olarak algılanarak hesaplamalara katılmıştır. Yükleme bittikten sonra çatlakların bir kısmı elastik toparlanma sonucu kapansa da bu durum her seride bulunacağından karşılaştırmalara etkisi çok az olacaktır. Dört farklı dilimdeki çatlak alanlarının ortalaması alınarak seriyi temsil eden çatlak alanı bulunmuş ve kırılma özelikleri ile ilişkilendirilmiştir. Şekil 3.7'de görüldügüü gibi uzun liflerin oranı \%1'den \%2'ye arttırıldığında çatlak alanı ve en büyük çatlak boyu belirgin bir şekilde artmıştır. KLB-\%3 serisi ile KLB- $\% 5$ serisinde uzun lifler aynı hacimde iken KLB-\%5 serisinde kısa liflerin oranının \%4'e çıkmasıyla ortalama çatlak alanı \%33, en büyük çatlak açıklığ $\% 6$ oranında artmıştır. Bu artış da çekme dayanımı ve tokluktaki belirgin artışla tutarlı bir sonuç vermiştir.

\section{SONUÇLAR}

Üretilen karma lifli betonlarda yapılan deneysel çalışmalar ve dijital görüntü analizleri ile aşağıdaki sonuçlara varılmıştır.

- Yapısal etkileri en aza indirecek şekilde tasarlanan deney düzeneği ile üç farklı lif içeriğindeki karma lifli betonlarda tek eksenli çekme yüklemeleri ile çatlama numunenin bir yüzünde başlamış ve göçme en doğal formunda sürmüştür. Lif hacmi arttıkça hem çekme dayanımı hem de betonun tokluğu artmıştır. Beklenildiği gibi, tepe yükteki deplasman ve tepe yükü sonrası köprülenme bölgesi artan lif miktarı ile artmıştır. Artan uzun lif miktarı ile çatlak açıklıkları yani deplasmanlar belirgin bir şekilde artmıştır. Kısa lif miktarının artması ise büyük miktarlarda tepe yükün artması ile sonuçlanmıştır. Çatlama alanındaki toplam lif miktarının artması ise liflerin köprülenmesi ve dolayısıyla çoklu-çatlama ile sonuçlanmıştır. Kısa liflerin yalnızca tepe yükünü arttırmadığı uzun lifler ile birlikte karma olarak kullanıldığında tepe yükünden sonraki davranışa da etkiyerek tokluğu da arttırdığı görülmüştür.

- Görüntü analizleri karma lifli betonlarda çatlağın hiçbir zaman doğrusal olmadığını betonun iç kısımlarına ilerledikçe dış yüzeyde görünmeyen çoklu çatlamanın, çatlak dallanmalarının ve çatlak köprülenmelerinin bulunduğunu göstermiştir. Kısa lifler arttıkça ortalama çatlak alanı belirgin bir şekilde artarken uzun liflerin miktarı arttıkça en büyük çatlak açıklığının arttığı belirlenmiştir. Çoklu çatlamanın fazla olması daha yüksek tokluğu oluşturmuştur. Böylece betonda belli bir değerdeki tokluk ve çekme dayanımının, lif hacim ve biçimlerinin değişik oranları ile elde edilebileceği görülmüştür.

\section{Teşekkür}

$\mathrm{Bu}$ çalışmadaki deneyler ETH-Zurich, Institute for Building Materials laboratuvarlarında sürdürülmüştür. 


\section{Kaynaklar}

[1] Rossi, P., Acker, P., Mallier, Y., Effect of steel fibres at two stages: the material and the structure. Mater. Struct., 20, 436-439, 1987.

[2] Mobasher, B., Li, C.Y., Mechanical properties of hybrid cement-based composites. ACI Mater. J., 93(3), 284-292, 1996.

[3] Yao, W., Li, J., Wu, K., Mechanical properties of hybrid fiber-reinforced concrete at low fiber volume fraction. Cem. Conc. Res., 33(1), 27-30, 2003.

[4] Lawler, J.S., Wilhelm, T., Zampini, D., Shah, S.P., Fracture processes of hybrid fiberreinforced mortar. Mater. Struct., 36(257), 197-208, 2003.

[5] Banthia, N., Gupta, R., Hybrid fiber reinforced concrete (HyFRC): fiber synergy in high strength matrices. Mater. Struct., 37(274), 707-716, 2004.

[6] Banthia, N., Sappakittipakorn, M., Toughness enhancement in steel fiber reinforced concrete through fiber hybridization. Cem. Conc. Res., 37(9), 1366-1372, 2007.

[7] Sahmaran, M., Yaman, I.O., Hybrid fiber reinforced self-compacting concrete with a high-volume coarse fly ash. Cons. Build. Mater., 21(1), 150-156, 2007.

[8] Kim, D.J., Park, S.H., Ryu, G.S., Koh, K.T., Comparative flexural behavior of Hybrid Ultra High Performance Fiber Reinforced Concrete with different macro fibers. Cons. Build. Mater., 25(11), 4144-4155, 2011.

[9] Kim, D.J., Park, S.H., Ryu, G.S., Koh, K.T., Tensile behavior of Ultra High Performance Hybrid Fiber Reinforced Concrete. Cem. Conc. Compos., 34(2), $172-$ 184, 2012.

[10] Akcay, B., Tasdemir, M.A., Mechanical behaviour and fibre dispersion of hybrid steel fibre reinforced self-compacting concrete. Cons. Build. Mater., 28(1), 287-293, 2012.

[11] Markovic, I., van Mier, J.G.M., Walraven, J.C., Development of high performance hybrid fibre concrete, Proceedings 4th International RILEM Workshop on High Performance Hybrid Fibre Concrete HPFRCC-4 (Naaman, A.E., Reinhardt, H.W., Eds.), RILEM Publications S.A.R.L., Bagneuax, France, Mainz, Germany, 277-300. 2003.

[12] van Mier, J.G.M., Reality behind the fictitous crack?, Proceedings of International Conference on Fracture of Concrete and Concrete Structures-FraMCos 5, Evanston, Illinois, 11-30, 2004.

[13] van Mier, J.G.M., Framework for a generalized four-stage fracture model of cementbased materials. Eng. Fract. Mech., 75(118), 5072-86, 2008.

[14] van Vliet, M.R.A., Size effect in tensile fracture of concrete and rock, PhD Thesis, Delft University of Technology, The Netherlands, 2000.

[15] Ferro, G., Effetti di scala sulla resisrenza a trazione dei materialli (Scale effects on tensile properties of materials), PhD thesis, Politecnico di Torino, 1994. 
[16] van Mier, J.G.M., Mode I fracture of concrete: discontinuous crack growth and crack interface grain bridging. Cem. Concr. Res., 21(1), 1-15, 1991.

[17] van Mier, J.G.M., Vervuurt, A., Schlangen, E., Boundary and size effects in uniaxial tensile tests: a numerical and experimental study, Proceedings of International Conference on Fracture and Damage of Quasi-Brittle Structures (Bazant, Z.P., Bittnar, Z., Jirasec, M., Mazars, J., Eds), E\&FN Spon, London/NewYork, I 289-302, 1994.

[18] van Mier, J. G.M., Mechtcherine, V., Minimum demands for deformation-controlled uniaxial tensile tests, RILEM TC 187-SOC, Experimental Determination of the StressCrack Opening Curve for Concrete in Tension (Planas, J. Ed.), Report 39, RILEM Publications S.A.R.L., Bagneux, France, 5-12, 2007.

[19] Gjorv, O.E., Sorenson, S., Arnesen, A., Notch sensitive and fracture toughness of concrete. Cem. Conc. Res., 7, 333-344, 1977.

[20] van Mier, J.G.M, Schlangen, E., Vervuur,t A., Tensile cracking in concrete and sandstone. Part II-effect of boundary conditions. Mater. Struct., 29(186), 87-96, 1996.

[21] Mechtcherine, V., Testing behaviour of strain hardening cement-based composites in tension - summary of recent research, Proceedings 5th international conference on High Performance Fiber Reinforced Cement Composites HPFRCC-5 (Reinhardt, H.W., Naaman, A.E., Eds.), RILEM Publications S.A.R.L., Bagneuax, France, Mainz, Germany, 3-12, 2007.

[22] Naaman, A. E., Fischer, G., Krstulovic-Opara, N., Measurement of tensile properties of fibre reinforced concrete: Draft submitted to ACI Committee 544. Proceedings 5th international conference on High Performance Fiber Reinforced Cement Composites HPFRCC-5 (Reinhardt, H.W., Naaman, A.E., Eds.), RILEM Publications S.A.R.L., Bagneuax, France, Mainz, Germany, 3-12, 2007.

[23] Akcay, B., Experimental investigation on uniaxial tensile strength of hybrid fibre concrete. Compos. Part B- Eng., 43(2), 766-778, 2012.

[24] Markovic, I., High Performance Hybrid Fibre Concrete-Development and Utilisation, PhD Thesis, Delft University of Technology, The Netherlands, 2006.

[25] Carpinteri, A., Ferro, G., Size effects on tensile fracture properties: a united explanation based on disorder and fractality of concrete microstructure. Mater. Struct., 10(2), 563$571,1994$.

[26] Schlangen, E., Experimental ad numerical analysis of fracture process in concrete, $\mathrm{PhD}$ Thesis, Delft University of Technology, The Netherlands, 1993.

[27] Stähli, P., van Mier, J. G. M., Manufacturing, fibre anisotropy and fracture of hybrid fibre concrete. Eng. Fract. Mech., 74, 223-242, 2007.

[28] Vořechovský, M., Interplay of size effects in concrete specimens under tension studied via computational stochastic fracture mechanics. Int. J. of Solids and Struct., 44(9), 2715-2731, 2007. 
